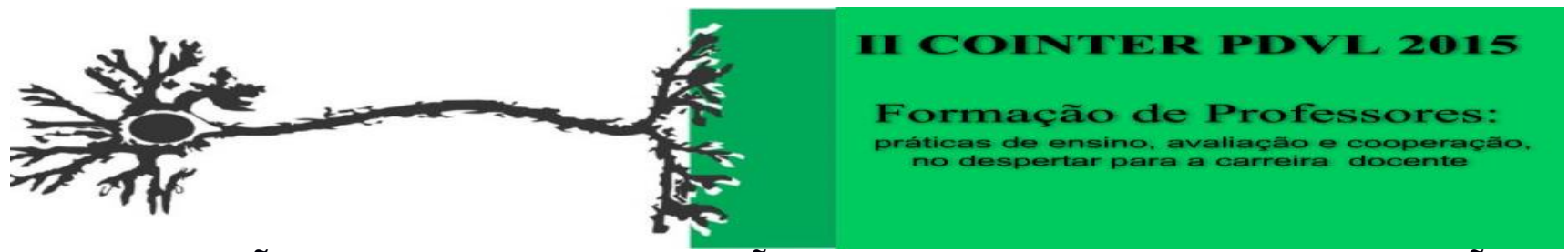

\title{
CONCEPÇÕES ACERCA DA AVALIAÇÃO DA APRENDIZAGEM: CONTRIBUIÇÕES DO CURSO DE PEDAGOGIA NA FORMAÇÃO DOCENTE.
}

\author{
Apresentação: Comunicação Oral \\ Natália de Pontes Leite Monte ${ }^{1}$; Kilma da Silva Lima Viana ${ }^{2}$
}

\section{Resumo}

O presente trabalho aborda a importância da formação docente quanto às concepções acerca de Avaliação da Aprendizagem, analisando as contribuições do componente curricular Avaliação Educacional no Curso de Pedagogia através dos oito princípios da Avaliação da Experiência (VIANA, 2014) que vem reconstruindo paradigmas acerca de Avaliação da Aprendizagem. A pesquisa teve cunho quali-quanti e foi realizada em uma das maiores Faculdades de Pedagogia do município de Vitória de Santo Antão através de um questionário fechado respondido por alunos e alunas do $5^{\circ}$ período do Curso de Pedagogia. Após a realização da revisão de literatura acerca da temática, a inquietação que serviu de mola propulsora para a realização dessa pesquisa foi: Quais são as contribuições que o componente curricular Avaliação Educacional, ofertado no curso de Pedagogia, oferece na formação das concepções dos professores acerca dos processos avaliativos? E, com o intuito de responder tal questionamento, o objetivo principal dessa pesquisa foi analisar as contribuições do componente curricular Avaliação na formação do pedagogo. Para isso, destacamos como objetivos específicos (i) identificar as concepções dos alunos que já cursaram a disciplina de Avaliação acerca dessa temática; (ii) relacionar estas concepções com os oito princípios da Avaliação da Experiência. Os resultados mostraram que $73 \%$ dos alunos que responderam o questionário possui uma grande abertura à reconstrução de novos conceitos acerca das práticas avaliativas, pois apresentam concepções voltadas para os princípios da Avaliação da Experiência (VIANA, 2014). Dessa forma, ressaltamos a necessidade de investimento na qualidade da formação docente a fim de contribuir cada vez mais para uma prática avaliativa inovadora e justa.

Palavras-Chave: Avaliação da Aprendizagem, Licenciatura em Pedagogia, Avaliação da Experiência.

\section{Introdução}

Atualmente, a Educação encontra-se num cenário que discutir novas metodologias e modelos de processos avaliativos é instigar à quebra de antigos paradigmas com o intuito de incentivar a busca de novos conceitos, e consequentemente, novas práticas. A todo o momento e em todos os lugares, a avaliação se faz naturalmente. Tanto na escola, como trabalho, entre os amigos e familiares, as pessoas estão averiguando e julgando as outras de formas distintas. O ato de avaliar tornou-se algo tão comum que as pessoas já o fazem inconscientemente. No âmbito educacional não é diferente. Este ocorre a todo instante, sem que necessariamente haja um instrumento que o formalize.

Segundo SAUL (2008, pg. 18) "Falar de avaliação é falar de gente, histórias, saberes,

\footnotetext{
${ }^{1}$ Graduanda em Licenciatura em Pedagogia, Faculdade Osman Lins (FACOL), monteingles@hotmail.com

${ }^{2}$ Doutora em Ensino de Física e Química, Universidade Federal Rural de Pernambuco, kilma.viana@vitoria.ifpe.edu.br
} 
práticas e compromissos", isto é, a avaliação deve ser concebida como um processo que relaciona a prática docente com a prática avaliativa, e não estar focada apenas em métodos, procedimentos e instrumentos, como é comumente compreendida. Ao questionar diferentes professores o significado de avaliação, percebe-se que esta possui várias definições e conceitos construídos a partir de suas experiências como alunos e mais tarde como docentes, portanto, essas diferentes concepções de avaliação corroboram para a construção de diferentes conceitos sobre educação. De acordo com SAUL (2008), a avaliação não é uma ação neutra, como muitos tentam fazê-la parecer. Para que sejam tomadas medidas em relação aos métodos, procedimentos e instrumentos de avaliação é necessário que estes estejam coerentes com a prática educativa, fazendo, assim, com que a prática avaliativa esteja diretamente ligada à prática educativa. Para FREIRE (1989) poderíamos dizer que as relações entre a prática avaliativa e docente são "vitais". Segundo FREIRE (1989, p.47, apud SAUL, 2008, p. 19 - 20):

"O trabalho de avaliar a prática jamais deixa de acompanhá-la. A prática precisa de avaliação como os peixes precisam de água e a lavoura da chuva. (...) Não é possível praticar sem avaliar a prática. Avaliar a prática é analisar o que se faz, comparando os resultados obtidos com as finalidades que procuramos alcançar com a prática. A avaliação da prática revela acertos, erros e imprecisões. A avaliação corrige a prática, melhora a prática, aumenta a nossa eficiência(...)" (FREIRE, 1989, p.47).

Portanto, é decerto afirmar que avaliação e prática devem se combinar e se completar. SAUL (1985) traz uma perspectiva crítico transformadora da avaliação, a qual denomina de Avaliação Emancipatória, ou seja, uma avaliação que supera os muros da medição e classificação, erguidos em métodos, procedimentos e instrumentos, e se compreende como um processo interligado com a prática docente e que faz o "aluno andar com as próprias pernas" (SAUL, 1985).

Segundo LUCKESI (2000) a avaliação da aprendizagem deve ser compreendida como recurso pedagógico capaz de auxiliar estudantes e professores na busca da construção do conhecimento de si mesmo e no "aprender a ser" que julgar melhor. Ela não deve continuar sendo uma ferramenta de ameaça e punição a que os discentes se submetem. A avaliação deve servir como auxílio para o aluno de forma a revisar e construir o conhecimento com base em seu ritmo de aprendizagem, e não ter um caráter unicamente classificatório e excludente. De acordo com LUCKESI (2000):

O ato de avaliar, devido a estar a serviço da obtenção do melhor resultado possível, antes de mais nada, implica a disposição de acolher. Isso significa a possibilidade de tomar uma situação da forma como se apresenta, seja ela satisfatória ou insatisfatória, agradável ou desagradável, bonita ou feia. Ela é assim, nada mais. Acolhê-la como está é o ponto de partida para se fazer qualquer coisa que possa ser feita com ela. Avaliar um educando implica, antes de mais nada, acolhe-lo no seu ser e no seu modo de ser, como está, para, a partir daí, decidir o que fazer. (LUCKESI, 2000, p. 02).

Essas novas concepções de avaliação dão vasão para uma compreensão muito mais ampla 
do ato de avaliar, onde o professor encontra-se responsável não só por tomar decisões a partir dos resultados que obtém de seus estudantes, mas principalmente avaliar seus estudantes com base no contexto em que se encontram, sem prejulgá-los ou condená-los.

Para HOFFMANN (2002), “A análise da aprendizagem é uma análise de conjunto de saberes e de fazeres. Esse aprender é um aprender muito mais amplo do que muitos professores hoje concebem", ou seja, a avaliação vai muito além do que simplesmente analisar o que o aluno sabe ou não. Avaliar, nessa perspectiva, é tomar consciência de que o aprender "envolve o desenvolvimento, o interesse e a curiosidade do aluno, a sua autoria como pesquisador, como escritor, como leitor" (HOFFMANN, 2002, p. 79), e o professor se coloca como mediador desse processo, facilitando, junto ao aluno, a construção dos saberes. HOFFMANN (2002) acredita que a avaliação deve estar ligada à essa concepção de conhecimento, onde exija uma observação individual de cada aluno no momento do processo de construção do conhecimento e não pode servir de punição ou ser ameaçadora, deve sim, ser uma mediação entre o aluno e o conhecimento. HOFFMANN (2002) defende a Avaliação Mediadora, onde o professor e o estudante são autores da prática avaliativa, porém, o professor, como parceiro mais experiente, tem o papel de facilitar esse processo servindo de mediador, e da mesma forma que isso acontece, a avaliação também tem seu papel mediador entre o estudante e a construção do conhecimento.

Baseada em todas essas discussões, inquieta-nos saber: Quais são as contribuições que o componente curricular Avaliação Educacional, ofertado no curso de Pedagogia, oferece na formação das concepções dos professores acerca dos processos avaliativos? E, com o intuito de encontrar respostas para esse questionamento, nossa pesquisa teve como objetivo geral analisar as contribuições do componente curricular Avaliação na formação do pedagogo. Para atingir esse objetivo procuramos (i) identificar as concepções dos alunos que já cursaram a disciplina de Avaliação acerca dessa temática; (ii) relacionar estas concepções com os oito princípios da Avaliação da Experiência (VIANA, 2014).

Essa inquietação surgiu a partir dos resultados dos estudos de Monte e Viana (2015), que ressaltam "a necessidade de uma melhor formação de professores em Avaliação para que, a cada dia, as práticas avaliativas possam contribuir significativamente para a formação moral, ética e intelectual do indivíduo". A partir dessas considerações, buscamos compreender se há um investimento na qualidade da formação dos professores quando diz respeito à Avaliação, visando uma contribuição significativa na construção do ser professor.

\section{Fundamentação Teórica}

A presente pesquisa teve como fundamentação teórica, as novas perspectivas propostas por 
Viana (2014), onde ressalta que mesmo aqueles professores que apresentam uma visão mais ampla sobre educação, que faz uso de metodologias mais inovadoras, participativas e interativas e que concebe avaliação como um processo contínuo e ligado ao ensino, suas práticas avaliativas continuam "com fortes aspectos excludentes, com viés autoritário, com o intuito de classificar e comparar o rendimento dos estudantes" (VIANA, 2014, p.16).

Em sua tese de doutorado, Viana (2014) tem como base filosófica o Alternativismo Construtivo (KELLY, 1955), que faz parte da Teoria dos Construtos Pessoais (KELLY, 1955), que afirma que o indivíduo "antecipa eventos" e concebe o mundo em geral a partir das experiências vividas anteriormente. E, ao fundamentar-se nas teorias de Kelly (1955), que considera a aprendizagem como uma experiência que acontece em cinco etapas, Viana (2014) defende uma nova perspectiva de Avaliação, denominada Avaliação da Experiência, estruturada em três pressupostos e oito princípios, que relacionam novas concepções acerca de ensino-aprendizagem e avaliação. Segundo Viana (2014):

"A perspectiva de avaliação, aqui apresentada, tem como base a Teoria dos Construtos
Pessoais, que é uma teoria psicológica, que apresenta diversas compatibilidades com as
ideias mais emergentes de avaliação, pois traz a ideia de Aprendizagem como uma
Experiência, que apresenta cinco etapas e que tem a avaliação como parte integrante do
processo de aprendizagem. Ressaltamos que, apesar de haver essa organização, o processo
avaliativo que se efetiva dentro desse ciclo, não é um roteiro, nem um modelo a ser seguido,
pois, assim como a experiência para Kelly (1963) não é estática (...)" (VIANA, 2014, p.176)

O primeiro pressuposto é A Avaliação como parte fundamental do processo de ensino e aprendizagem. Como já mencionado, essa perspectiva avaliativa rompe paradigmas inerentes aos modelos mais tradicionais, onde avaliação é tida como algo que destoa do processo de ensino e tem por objetivos medir e classificar o estudante sempre ao final das etapas. Para Viana (2014) a avaliação "dá informações de como vem sendo desenvolvido tanto o ensino, quanto a aprendizagem" (VIANA, 2014, p.176).

O segundo pressuposto da Avaliação da Experiência é o caráter mutável das concepções. Ao considerar que "as concepções são mutáveis, passíveis de revisões” (p. 176), Viana (2014) defende que a revisão é extremamente importante porque é através dela que o processo avaliativo deixa de ser "um momento de sofrimento, ou simples prestação de contas" (p. 176), e passa a ter um caráter construtivo que promove a aprendizagem de maneira mais significativa.

O terceiro pressuposto é Avaliação como instrumento de transformação, que transcende uma perspectiva estática da avaliação. A transformação citada poderá ocorrer com base nas cinco etapas do ciclo de construção da Avaliação da Experiência que está fundamentado no Ciclo da Experiência Kellyana (KELLY, 1955) que são: Antecipação, Investimento, Encontro, Confirmação ou Desconfirmação e Revisão Construtiva. 
Na primeira etapa (Antecipação), o professor pode fazer uso de uma avaliação diagnóstica tanto para conhecer os conhecimentos prévios dos estudantes, tanto para antecipar quais assuntos deverão ser abordados na prática e quais estratégias pedagógicas poderão ser utilizadas com base nos construtos de seus estudantes. Nessa etapa, os estudantes conhecerão a proposta do professor, podendo fazer acordos sobre ela e também poderão refletir sobre o que já sabem sobre os "novos" conceitos que será abordado. Na segunda etapa (Investimento), o professor e os estudantes "investem" no conteúdo através de debates, discussões e estudos no intuito de se prepararem para a etapa seguinte. Esta, por sua vez, é a etapa do Encontro, onde os conteúdos abordados são construídos de forma coletiva e os estudantes ao final terão a possibilidade de Confirmar ou Desconfirmar as hipóteses levantadas inicialmente enquanto participavam das etapas de Antecipação e Investimento. A etapa da Confirmação ou Desconfirmação é estruturada em instrumentos avaliativos os quais estudantes e professores possam avaliar todo o processo de construção do ensino-aprendizagem. E, finalmente, a quinta etapa do ciclo, é a Revisão Construtiva, onde tanto o professor quanto os estudantes poderão refletir sobre mudanças de concepções ocorridas durante todo o processo. Dessa forma, na perspectiva da Avaliação da Experiência, os estudantes tem a oportunidade de descontruírem, construírem e/ou reconstruírem o conhecimento de forma única e a partir de suas vivências através da prática avaliativa, pois em todas as etapas o estudante está envolvido na avaliação.

Os princípios que norteiam a Avaliação da Experiência apresentam-se em oito: O primeiro, Princípio da Negociação, resulta em um diálogo entre o professor e o estudante de forma a decidirem juntos, qual o caminho a ser seguido no processo avaliativo. Para Viana:

Essa negociação deve estar presente desde as decisões sobre quais os instrumentos deverão e poderão ser utilizados para avaliar um determinado aspecto do processo educativo, até os momentos em que devem ser utilizados, às formas de utilização e os seus encaminhamentos. (2014, p. 178)

Consideramos esse um dos principais aspectos desse novo modelo avaliativo, tendo em vista que é a partir dele que o estudante torna-se responsável também pelo seu próprio processo de ensino-aprendizagem através da avaliação. Ela ressalta ainda que a negociação deve ser mediada pelo professor, mas ele tem o dever de "assegurar a disponibilidade para a escuta dos argumentos dos estudantes" (VIANA, 2014, p. 179).

O segundo é o Princípio do Acolhimento, pois Viana (2014) defende que para que haja uma negociação plena e livre de "conflitos" é extremamente importante que um acolha a opinião do outro, tornando assim o processo justo e saudável. Para ela, esse é o princípio que garante que as pessoas "de posições diferentes, divergentes, possam buscar o ponto de convergência, o consenso" 
(VIANA, 2014, p. 179), afinal, numa sala de aula existem alunos com diferentes concepções, cotidianos e pré-conceitos acerca dos conteúdos, e cabe ao professor, fazer essa mediação de forma afetiva e acolhedora. Ressalta, ainda, que "essa perspectiva de avaliação tem, nesse princípio, o resgate da essência da avaliação, que é cuidar do processo de ensino e aprendizagem, sentar ao lado e acolher o outro" (VIANA, 2014, p. 180).

O terceiro, Princípio da Confiança, relaciona-se com os demais, pois para Viana (2014) deve-se ir muito além do "ritual de barganha" que acontece no âmbito educativo onde "o professor ensina e o estudante aprende, depois professor avalia e o estudante devolve para o professor o que ele ensinou" (VIANA, 2014, p. 180). Nessa nova proposta a afetividade reassume sua posição em lugar da animosidade e esse princípio "resgata o caráter humano da avaliação e tem como base as relações afetivas" (p. 180), superando, assim, o caráter ameaçador e tenso que o processo avaliativo exerce.

O quarto princípio é o Princípio da Proatividade. Para que os outros - negociação, acolhimento e confiança - ocorram, é necessária uma postura proativa de ambas as partes, pois sem ela esses acordos se prejudicam. Quando todos se dispõem a vivenciar o novo, partindo dessa proatividade, as práticas avaliativas deixam de ser estáticas e as tomadas de decisão tornam-se mais dinâmicas. "Os acordos realizados no início do processo, não precisam ser considerados intocáveis. Podem ser refeitos, rediscutidos, revisitados sempre que necessário" (VIANA, 2014, p.180).

Já o Princípio Crítico-Reflexivo visa transformar o papel de padronização, memorização e reprodução de conteúdo, que as práticas avaliativas assumem desde os primórdios. Viana (2014), defendendo que avaliação e ensino fazem parte de um mesmo processo, ressalta que o estudante é um ser ativo no processo de construção do conhecimento. Nessa perspectiva, a ideia de provas tradicionais deve ser superada por avaliações que busquem a formação crítica do estudante.

Nessa reflexão, Viana (2014) traz o Princípio da Emancipação, assumindo que a Avaliação da Experiência é "antes de tudo, político-social, pois busca formar indivíduos, além de críticos, reflexivos, também emancipados, autônomos. Por esse motivo, não dialoga com vertentes que entendem o processo educativo de subordinação, passividade e dependência" (182). Dessa forma, o professor deve prezar por estratégias avaliativas que instiguem o estudante a gerir o seu próprio processo de ensino-aprendizagem.

Entretanto, Viana (2014) também defende o Princípio do Compartilhamento, que supera a proposta de interação, pressupondo uma perspectiva de colaboração, onde todos compartilham as responsabilidades e os sentimentos. Segundo Viana (2014, p.182) “em momentos de negociação, de troca, de partilhamentos, é comum que ocorram crises, cansaços, desgastes e insatisfações” e é por esse motivo que a Avaliação da Experiência está fundamentada em princípios que resgatam esse 
caráter humano da avaliação.

O Princípio Ético, que "é pano de fundo de todas as relações estabelecidas na Avaliação da Experiência e é essencial nos momentos de negociação, decisões, reencaminhamentos e compartilhamentos de responsabilidades” (p. 183), define uma avaliação justa alicerçada em relações de confiança. De acordo com Viana (2014):

Ser ético, no processo avaliativo, é decidir baseado em critérios claros e acordados. É utilizar os resultados da avaliação para auxiliar na formação e no crescimento dos estudantes. É considerar as diferenças, os ritmos e as formas de aprender de cada um e é, antes de tudo, considerar que todos têm direito de aprender (2014,p. 183).

Diante de tudo o que foi exposto, a Avaliação da Experiência traz uma nova perspectiva e condena veemente a prática avaliativa tradicional, que tem a única finalidade de medir e classificar os estudantes, que por sua vez, apresentam-se apenas como depósito de informações e reprodutivistas de conteúdos. A Avaliação da Experiência respeita a individualidade de cada um, busca o compartilhamento de responsabilidades e saberes, é ética, e tem como objetivo fazer do processo avaliativo uma prática mais justa e acolhedora.

\section{Metodologia}

Esta é uma pesquisa etnográfica de natureza quali-quanti, realizada em uma das maiores Faculdades de Pedagogia da região. Os sujeitos da pesquisa foram todos os alunos e alunas do $5^{\circ}$ período do Curso de Licenciatura em Pedagogia, visto que o componente curricular Avaliação Educacional é ofertado no $4^{\circ}$ período, segundo a matriz curricular do curso em foco da Instituição selecionada. Na ocasião da coleta de dados, apenas 27 dos 35 alunos da turma estavam presentes e responderam o questionário.

Para a coleta dos dados analisados, os alunos foram submetidos a um questionário fechado que contemplava oito itens fundamentados nos princípios da Avaliação da Experiência (VIANA, 2014), dentre eles: (I) Para você o que é avaliação? (eles tinham a opção de marcar dentre duas a alternativa que mais se aproximava de suas concepções); (II) $\mathrm{O}$ aluno deve fazer parte das decisões referentes ao processo avaliativo juntamente com o professor através da busca por consensos. (concorda/discorda); (III) O planejamento deve ser rigorosamente cumprido, sem flexibilidade, mesma que haja a necessidade de rever o conteúdo com base nos resultados da avaliação (concorda/discorda); (IV) O professor deve acolher a opinião do aluno quanto à sua prática avaliativa (concorda/discorda); (V) É fundamental que o professor adeque sua prática avaliativa às necessidades doa alunos (concorda/discorda); (VI) Até que ponto a relação de confiança entre aluno e professor influencia no processo avaliativo? (muito/pouco/não influencia); (VII) Qual(is) instrumento(s) você considera mais importante no processo avaliativo? (os alunos tinham seis 
opções de instrumento avaliativo e podiam marcar quantos quisessem); (VIII) O componente curricular Avaliação Educacional mudou suas concepções acerca da prática avaliativa? (muito/pouco/não mudou).

Com base nos dados coletados, pudemos analisar criteriosamente as contribuições que o componente curricular Avaliação Educacional proporcionou aos alunos e alunas do curso de Pedagogia.

\section{Resultados e Discussão}

Com a análise dos dados da pesquisa observamos as contribuições que a disciplina de Avaliação promoveu aos graduandos e obtivemos os seguintes resultados:

- Quanto à aproximação das concepções dos alunos com as perspectivas da Avaliação da Experiência:

74\% dos alunos apresentam concepções voltadas para a perspectiva da Avaliação da Experiência (VIANA, 2014), pois associam o ato de avaliar à um processo de acompanhamento através de diversos instrumentos avaliativos no intuito de redimensionar o processo de ensinoaprendizagem. Além disso, eles concebem avaliação como um compartilhamento de responsabilidades ao decidirem juntos, professor e aluno o melhor caminho no processo avaliativo através da busca por consensos.

Os $26 \%$ dos alunos restantes permanecem com concepções voltadas para as gerações mais tradicionais da Avaliação quando afirmam que a prática avaliativa é um processo de medição do conhecimento e de checagem dos objetivos da disciplina. Além do mais, relacionam o processo à verificação da aprendizagem sem mencionar a reconstrução dos saberes através de revisões e auto avaliação.

- Quanto ao princípio da Negociação e do Compartilhamento:

$70 \%$ dos alunos afirmaram que o processo avaliativo deve ser definido pelo professor juntamente com o aluno, numa busca por consensos. Dessa forma, o professor compartilha responsabilidades com o aluno, tornando-o, também, protagonista do seu próprio processo avaliativo. Enquanto que apenas $30 \%$ discordam que prática avaliativa deve ser regida por um processo de negociação e compartilhamento.

- Quanto ao princípio da Proatividade:

$56 \%$ dos graduandos acreditam que deve haver uma flexibilidade no planejamento, pois o mesmo pode ser reestruturado a partir dos resultados do processo avaliativo de acordo com o contexto dos alunos. Contudo, $44 \%$ concordam com a rigorosidade no cumprimento do planejamento nos prazos estabelecidos. É importante destacar que este foi um dado inesperado, 
visto que a Proatividade é um princípio fundamental quanto às perspectivas da nova Avaliação, e, contraditoriamente a este, a maioria dos alunos apresentou concepções voltadas à essa Avaliação mais emergente e inovadora.

- Quanto ao princípio do Acolhimento:

$100 \%$ dos licenciandos concordaram que o professor deve acolher a opinião do aluno quanto à sua prática avaliativa, adequando-a, dessa maneira, às necessidades dos alunos. Além disso, ao acolher a opinião do aluno, o professor estará, consequentemente, promovendo a formação de um indivíduo autônomo e emancipado.

- Quanto ao princípio da Ética:

$100 \%$ dos alunos concordaram que é primordial que o professor adeque sua prática avaliativa às necessidades dos alunos. Nesse intuito, ao regular sua prática avaliativa ao contexto dos alunos, o professor estará promovendo uma Avaliação mais justa e ética, onde os alunos podem expressar e desenvolver suas habilidades e competências através do processo avaliativo que ajustese à sua realidade, descartando a possibilidade de uma avaliação punitiva e classificatória.

- Quanto ao princípio da Confiança:

93\% dos alunos acreditam que a relação de confiança docente-discente tem uma grande influência no processo avaliativo. Dessa forma, esta prática transcende ao "ritual de barganha" (VIANA, 2014), onde o professor ensina e o aluno deve "devolver" a ele, durante o processo avaliativo, exatamente aquilo que the foi passado. Numa relação de confiança, o professor compreende e conhece o que o aluno aprendeu e este, por sua vez, confia na prática de avaliação do professor. Todavia, 7\% dos alunos não acreditam que as relações de confiança entre professor e aluno influenciam no processo.

- Quanto ao princípio Crítico-Reflexivo e da Emancipação:

Apenas 19\% dos graduandos apresentaram concepções acerca do uso dos instrumentos avaliativos de forma variada e precisa. Estes acreditam na formação de um aluno crítico-reflexivo a priori, pois a utilizar vários instrumentos avaliativos em sua prática, está buscando adequar-se ao contexto de cada um, desenvolvendo assim suas habilidades operatórias. No entanto, $81 \%$ dos estudantes mostraram que não fazem uso de muitos instrumentos avaliativos, portanto é decerto afirmar que ainda estão voltados para perspectivas mais tradicionais de Avaliação ao fundamentarem suas práticas em checagem e confirmação de conteúdo.

- Quanto às mudanças nas concepções dos estudantes de Pedagogia que o componente curricular Avaliação Educacional proporcionou:

$70 \%$ dos licenciandos afirmaram que a disciplina Avaliação Educacional promoveu uma 
grande mudança nas concepções que eles possuíam acerca de Avaliação. Segundo LIMA (2008), a maior parte dos professores constroem suas concepções acerca de Avaliação e elaboram seu modo de avaliar influenciados pelas práticas avaliativas de seus próprios professores. Dessa forma, é possível afirmar que essa influência pôde ser minimizada depois que os alunos cursaram a disciplina de Avaliação Educacional.

Com os resultados dos dados obtidos, percebemos que a maior parte dos licenciandos em Pedagogia já apresentam fortes características da Avaliação da Experiência, que é de uma geração completamente emergente e atual (vide gráfico 1).

Gráfico 1 - Comparação das concepções dos alunos do $5^{\circ}$ período do Curso de Licenciatura em Pedagogia entre Avaliação da Experiência e Avaliações Tradicionais - 2015.

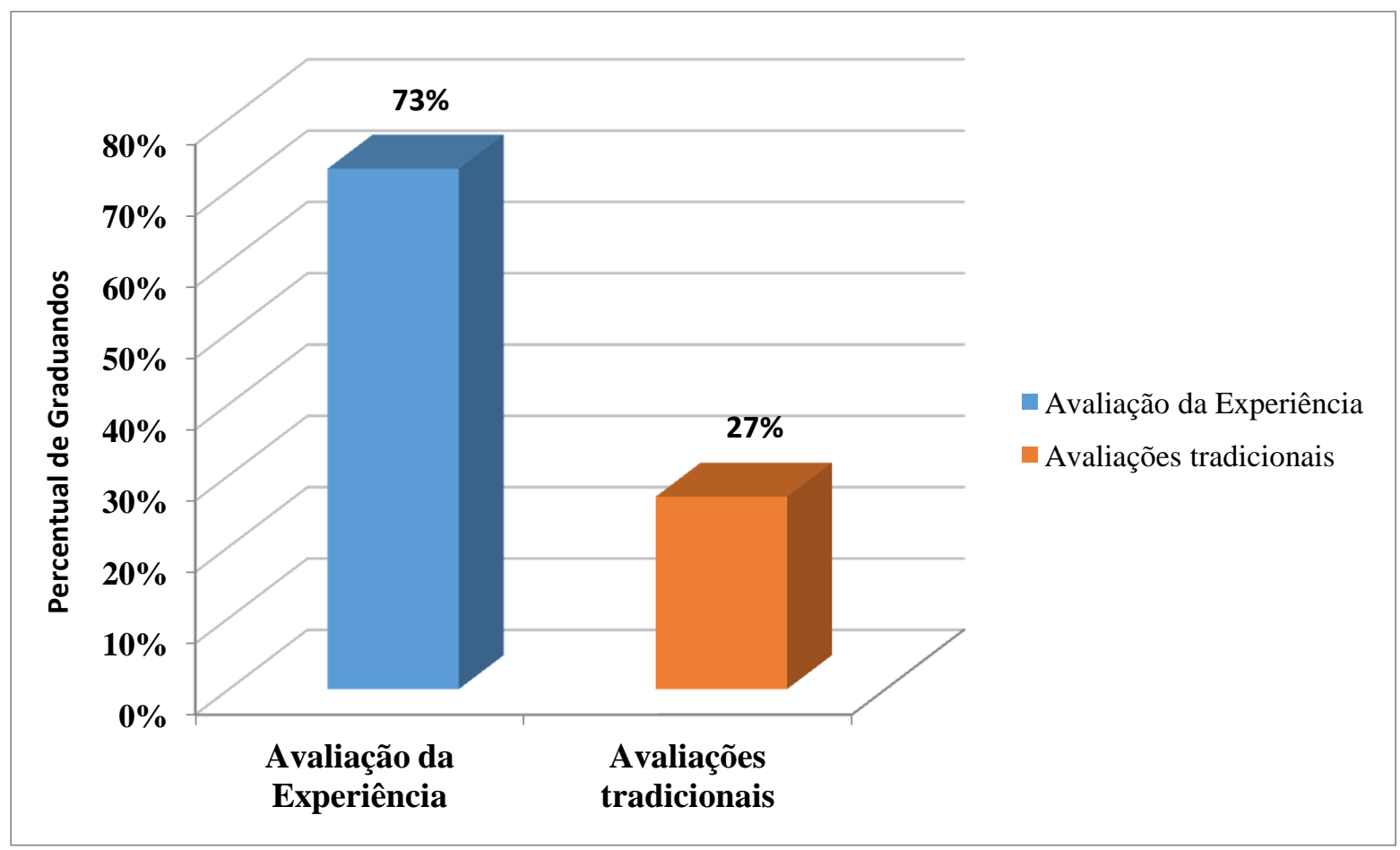

Fonte: Própria.

\section{Conclusões}

A partir dos resultados obtidos após a análise e discussão dos resultados, pudemos analisar criteriosamente as contribuições que a disciplina Avaliação Educacional proporciona aos graduandos, ressaltando a importância do investimento das Instituições de Ensino Superior na formação dos professores no que diz respeito à Avaliação da Aprendizagem. Podemos afirmar, ainda, que enquanto pedagogos formados, os alunos analisados possivelmente trabalharão de forma proativa, deixando-se experimentar novos caminhos ao flexibilizar o processo de ensinoaprendizagem; compartilharão responsabilidades dos processos avaliativos com os seus alunos e, 
até mesmo, suas famílias; terão como objetivo profissional principal a formação de pessoas autônomas e emancipadas, construindo juntamente com seus alunos o ser crítico e reflexivo; agirão de forma acolhedora, respeitando as opiniões e os limites dos alunos; e por fim, estarão se aproximando de uma Avaliação mais ética e justa, a fim de conhecer o universo do aluno e adaptarse à seu cotidiano.

Destacamos, no entanto, que apesar de suas concepções, a utilização de instrumentos variados ainda não faz parte da prática avaliativa, pois $81 \%$ dos estudantes ainda apresentam ênfase em instrumentos tradicionais. Esse resultado é bastante importante, pois é preciso a sua superação.

Sendo assim, ressaltamos mais uma vez a enorme importância de uma formação docente de qualidade, observando que essa formação, voltada para a Avaliação da Aprendizagem, traz enormes contribuições nas concepções dos graduandos e, principalmente, na formação do ser professor e dessa maneira, o investimento em formações mais aprofundadas acerca da avaliação (nas questões teóricas e práticas) auxiliarão na mudança efetiva da prática.

\section{Referências}

HOFFMAN, J. Avaliação mediadora: uma prática em construção da pré-escola à universidade. Porto Alegre: Mediação, 2001.

LIMA, K. S. Compreendendo as concepções de avaliação de professores de física através da teoria dos construtos pessoais. Recife, 2008. 163 p. Dissertação (Ensino das Ciências). Departamento de Educação, UFRPE, 2008.

KELLY, G. A. A theory of personality: the psychology of personal constructs. New York: W.W. Norton, 1963.

LUCKESI, C. C. O que é mesmo o ato de avaliar aprendizagem?. Porto alegre: Artmed. Ano 3, n.12. fev.2000. Disponível em:

<https://www.nescon.medicina.ufmg.br/biblioteca/imagem/2511.pdf>. Acesso em: 20. jul. 2015.

MONTE, N. P. L.; VIANA, K. S. L. Concepções e prática avaliativa no ensino da língua inglesa: uma análise através da perspectiva da Avaliação da Experiência. In: II Congresso Nacional de Educação, 2015, Campina Grande - PB. Anais do II Congresso Nacional de Educação, 2015.

SAUL, A. M. Avaliação emancipatória: desafio à teoria e à prática de Avaliação e reformulação de currículo. 5 ed. São Paulo: Cortez, 2000.

Referenciais Freireanos para a prática da avaliação. Revista de Educação PUC-

Campinas, Campinas, n. 25, p. 17-24, nov. 2008. Disponível em: <http://periodicos.puccampinas.edu.br/seer/index.php/reveducacao/article/view/90>. Acesso em: 20. jul. 2015. 
VIANA, K. S. L. Avaliação da Experiência: uma perspectiva de Avaliação para o ensino das Ciências da Natureza. 2014. 212f. Tese (Doutorado em Ensino de Física e Química) - Universidade Federal Rural de Pernambuco - UFRPE, Recife, 2014. 